\title{
Are the Naica giant crystals deteriorating because of human action?
}

\author{
M. E. Montero-Cabrera (1), ${ }^{1, a)}$ I. J. A. Carreño-Márquez, ${ }^{1}$ I. Castillo-Sandoval, ${ }^{1}$ B. Pérez-Cázares, ${ }^{2}$ \\ L. E. Fuentes-Cobas, ${ }^{1}$ H. E. Esparza-Ponce, ${ }^{1}$ E. Menéndez-Méndez, ${ }^{3}$ M. E. Fuentes-Montero, ${ }^{2}$ \\ H. Castillo-Michel, ${ }^{4}$ D. Eichert, ${ }^{5}$ R. Loredo-Portales, ${ }^{6}$ J. Canche-Tello, ${ }^{1}$ M. Y. Luna-Porres, ${ }^{1}$ \\ G. González-Sánchez, ${ }^{1}$ D. Burciaga-Valencia, ${ }^{1}$ C. Caraveo-Castro, ${ }^{1}$ G. Gómez-Méndez, ${ }^{2}$ \\ L. Muñoz-Castellanos, ${ }^{2}$ and I. Reyes-Cortes ${ }^{2}$ \\ ${ }^{1}$ Centro de Investigación en Materiales Avanzados (CIMAV), Chihuahua 31136, Mexico \\ ${ }^{2}$ Universidad Autónoma de Chihuahua, Chihuahua 31125, Mexico \\ ${ }^{3}$ Instituto Eduardo Torroja de Ciencias de la Construcción, Madrid 28033, Spain \\ ${ }^{4}$ European Synchrotron Radiation Facility, Grenoble Cedex 9 38043, France \\ ${ }^{5}$ Elettra Sincrotrone Trieste S.C.p.A., AREA Science Park, Basovizza (Trieste) 34149, Italy \\ ${ }^{6}$ Universidad Nacional Autónoma de México, Hermosillo 83000, Mexico
}

(Received 11 November 2019; accepted 14 April 2020)

\begin{abstract}
The giant gypsum crystals of Naica cave have fascinated scientists since their discovery in 2000 . Human activity has changed the microclimate inside the cave, making scientists wonder about the potential environmental impact on the crystals. Over the last 9 years, we have studied approximately 70 samples. This paper reports on the detailed chemical-structural characterization of the impurities present at the surface of these crystals and the experimental simulations of their potential deterioration patterns. Selected samples were studied by petrography, optical and electronic microscopy, and laboratory X-ray diffraction. 2D grazing incidence X-ray diffraction, X-ray $\mu$-fluorescence, and X-ray $\mu$-absorption near-edge structure were used to identify the impurities and their associated phases. These impurities were deposited during the latest stage of the gypsum crystal formation and have afterward evolved with the natural high humidity. The simulations of the behavior of the crystals in microclimatic chambers produced crystal dissolution by $1-4 \%$ weight fraction under high $\mathrm{CO}_{2}$ concentration and permanent fog, and gypsum phase dehydration under air and $\mathrm{CO}_{2}$ gaseous environment. Our work suggests that most surface impurities are of natural origin; the most significant anthropogenic damage on the crystals is the extraction of water from the caves. () 2020 International Centre for Diffraction Data. [doi:10.1017/S0885715620000287]
\end{abstract}

Key words: gypsum crystals, Naica caves, elemental impurities, microclimatic chamber simulations, chemical-structural characterization

\section{INTRODUCTION}

Naica is constituted by three minor mountain chains located in the northern Mexican state of Chihuahua that form a large dome in the direction NW-SE. The GPS coordinates of the Naica mine are $27^{\circ} 51^{\prime} 3^{\prime \prime} \mathrm{N}$ and $105^{\circ} 29^{\prime} 47^{\prime \prime} \mathrm{W}$. This mine produces lead, zinc, and silver. The Naica mine comprises several caverns, amongst them, the two main caves, named the Cave of Swords and the Cave of Crystals, in which one can find the famous "giant crystals." The Cave of Swords contains gypsum $\left(\mathrm{CaSO}_{4} \cdot 2 \mathrm{H}_{2} \mathrm{O}\right)$ single crystals of up to $1 \mathrm{~m}$ in length. It is found at a depth of $120 \mathrm{~m}$ and was discovered in 1910. The Cave of Crystals was discovered in the year 2000. It contains the most spectacular crystals in the world (Figure 1). The cave is at a depth of $290 \mathrm{~m}$, at the end of one labyrinth in the mine. The crystals that have grown inside the cave are similar to the beams of buildings and measure more than $10 \mathrm{~m}$ in length and $1 \mathrm{~m}$ in diameter. They are composed of transparent gypsum, a soft, hydrated calcium sulfate mineral which, under perfect conditions

\footnotetext{
${ }^{\text {a) }}$ Author to whom correspondence should be addressed. Electronic mail: elena.montero@cimav.edu.mx
}

of crystallization, occurs in the "selenite" variant (Van Driessche et al., 2019).

The extraordinary conditions that occurred in Naica to promote the formation of these selenite crystals were, for the most important ones, the presence of water containing a proper concentration of calcium sulfate; a constant temperature of about $55^{\circ} \mathrm{C}$; a permanent water supply, and very few movements of the earth's crust. These conditions lasted approximately 1 million years, time that mother Nature took to create this exceptional wonder (Van Driessche et al., 2011).

During mining activities, the groundwater is pumped out of the mine area. This action has resulted in lowering the water table well below the level of the caves. Consequently, the giant crystals are exposed to an atmosphere with humidity close to $100 \%$ and temperature of the order of $50{ }^{\circ} \mathrm{C}$. Furthermore, mining activities do not only require to carry out underground explosions, but also produces gases such as carbon oxides $\left(\mathrm{CO}_{x}\right)$ and nitrogen oxides $\left(\mathrm{NO}_{x}\right)$ which, mixed with water, lead to acidic solutions. Likewise, methane is a common ground gas present in mines.

It is well known that the crystalline gypsum structure generates planes of water molecules (Van Driessche 


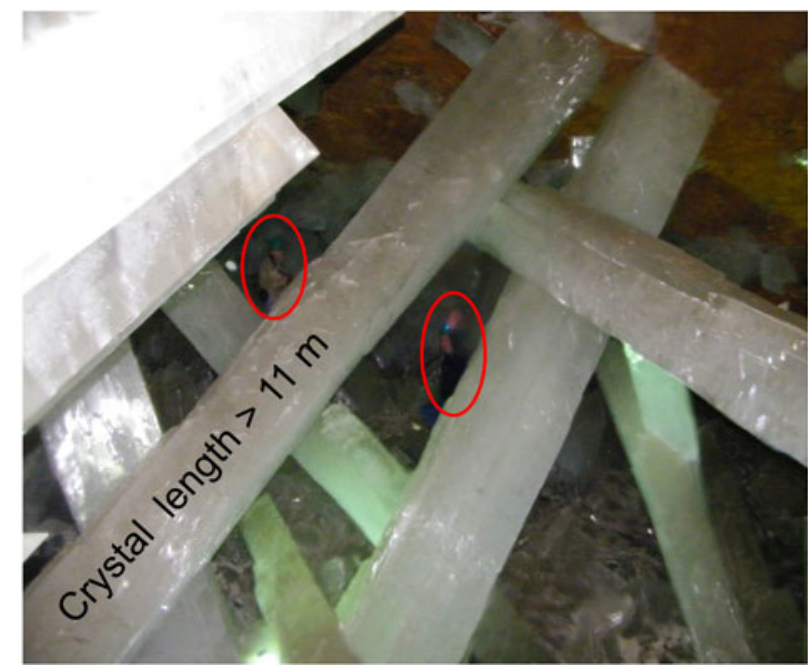

Figure 1. (Color online) View of the Cave of Crystals. In the background, one can distinguish the figure of two persons (encircled in red), which gives a scale of reference.

et al., 2017). The water associated with the gypsum can evaporate in gaseous environments, causing the dehydration of these planes. As a consequence, bassanite appears, organizing the remaining water molecules into water channels. The mining conditions may lead then to destabilization and dissolution of the gypsum crystals. Furthermore, the $\mathrm{CO}_{2}$ produced by combustion and human breathing may cause the deposition of calcium carbonate on the surface of the crystals. These environmental changes have, therefore, the potential to generate both chemical and physical processes, which may impair the integrity of the crystal structures. The objective of the current project was to clarify whether these impurities have a natural or anthropogenic origin.

At present, observations undertaken inside the Cave of Crystals show that these almost perfect crystals display only a few impurities at the surface, which study may contribute to understanding the processes the giant crystals were subjected to. The present work reports the detailed characterization of representative samples of these caves to clarify the origins and causes of the appearance of these impurities, which tend to darken the surface of some of the giant crystals and may reduce their beauty. Unraveling their chemical composition and their phases, taking into consideration the current environmental conditions of the caves, is the first aspect investigated in this paper. The second is the simulation of controlled experimental conditions that can lead to the deposition of impurities on selenite crystals and their degradation.

\section{EXPERIMENTAL}

\section{A. Samples}

A stock of about 70 individual samples were made available for investigations to our laboratory: 30 samples are coming from the Cave of Swords (CS) and 40 samples from the Cave of Crystals (CC). Most samples are issued from private collections, universities, and state museums, where they were displayed in showcases. The largest one, a "blocky" type crystal from the $\mathrm{CC}$, was a donation from the Naica mine management to research activities. From this stock collection, only samples presenting some surface impurities were studied. They were selected after visual inspection and optical microscopy: 10 originated from the CS and 20 from the CC. The characterization of CS samples has been described in Castillo-Sandoval et al. (2018) and is included here in the discussion for comparison. In Table I, the abbreviations for the 20 samples from the $\mathrm{CC}$ are given, together with the different methods used, which are briefly described in the corresponding sections. The four samples GYP001 to 004 (CC) are the first four samples, provided by the Faculty of Engineering of the Autonomous University of Chihuahua, in 2013. They were studied by optical microscopy at our laboratory CIMAV and at Stanford Synchrotron Research Light source (SSRL) by 2D grazing incidence X-ray diffraction (GI-XRD) and micro X-ray fluorescence $(\mu-\mathrm{XRF})$. The four samples type CRYD001 to 004 (CC) were provided by the Chihuahua Desert Museum, Ciudad Delicias, Chihuahua, in 2014. The four samples CRYD005 to 008 (CC) were provided by members of the Association of Mining Engineers, Metallurgists, and Geologists of Mexico, also in 2014. These were studied only by optical methods at CIMAV. The eight samples CRYSN001 to 008 (CC) were collected by Castillo-Sandoval at the entrance of the cave in 2016. They were studied at CIMAV, Elettra - Sincrotrone Trieste, and at the European Synchrotron Radiation Facility (ESRF). Some representative samples of the studied specimens with surface impurities, including the "blocky" type crystal, are presented in Figure 2. One of those samples was provided by the Laboratory for Crystallographic Studies, University of Granada. This sample was observed by optical microscopy, and no surface impurities were found on or in it.

\section{B. Methods}

In the present research, conventional laboratory techniques such as petrography, optical and electron microscopy, or laboratory X-ray diffraction were combined to synchrotron radiation-based techniques. 2D GI-XRD, $\mu$-XRF, and $\mu$-X-ray absorption near-edge structure ( $\mu$-XANES) allowed identifying the elemental and structural composition of the impurities,

TABLE I. Working names from 20 individual samples studied from the Cave of Crystals and used techniques.

\begin{tabular}{|c|c|c|c|c|c|c|c|}
\hline Samples names & Optical microscopy & LCM-DIM & XRD & GI-XRD & SEM-EDS & $\mathrm{SR} \mu$-XRF & SR $\mu$-XANES \\
\hline GYP001 to 004 & YES & & & & & YES & YES \\
\hline CRYD001 to 008 & YES & YES & & & & & \\
\hline CRYSN001 to 008 & YES & YES & & YES & & YES & YES \\
\hline CRYD001 to 002 & & & YES & & YES & & \\
\hline GYP001 & & & & YES & & YES & YES \\
\hline CRYD001 & & & & YES & & YES & YES \\
\hline
\end{tabular}



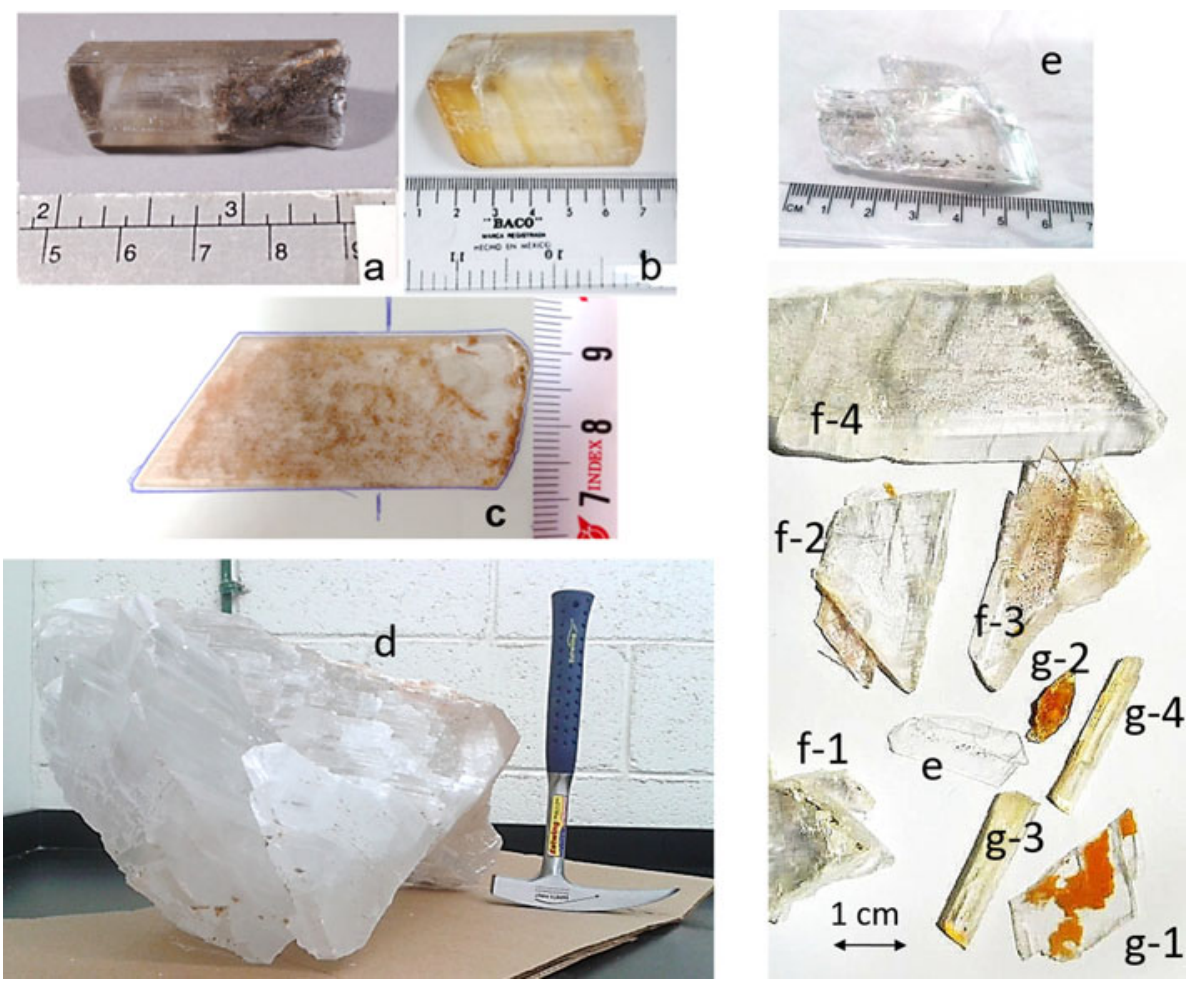

Figure 2. (Color online) Representative samples from both the CS and the CC. (a) Sample provided by the Harvard Museum of Natural History (CS); (b) "yellowish" sample (CS); (c) "reddish" sample (CS); (d) Blocky giant crystal donated by the Naica mine management (CC); (e) sample provided by the Laboratory for Crystallographic Studies, University of Granada (CC); (f) "GYP001 to 004" samples (CC); (g) CRYD001 to 004 samples, provided by the Chihuahua Desert Museum, Ciudad Delicias, Chihuahua (CC). Samples (f) were provided by the Faculty of Engineering of the Autonomous University of Chihuahua (CC). Figures from samples (a-c) are reproduced with Copyright permission from Castillo-Sandoval et al. (2018).

and especially discriminating the phase of the specific mineral in which these are contained. The equipment used is briefly listed below.

Laser confocal microscopy-differential interference contrast microscopy (LCM-DIM) was employed to acquire a contrast image of a transparent sample for the identification of some elements. Samples were visualized with an LSM 700 (Zeiss, Jena, Germany) system equipped for DIM. Solid-state green $(555 \mathrm{~nm}, 10 \mathrm{~mW})$ and red $(639 \mathrm{~nm}, 5 \mathrm{~mW})$ lasers were used.

Petrography analysis was undertaken using an Olympus BX41 microscope at a maximum of $20 \times$ amplification.

For scanning electron microscopy (SEM) investigation, the selected gypsum single crystals were exfoliated along their natural $(0,1,0)$ cleavage planes. Secondary and backscattering electron images were obtained using SEM Hitachi SU3500. Qualitative and semi-quantitative elemental analysis in the energy-dispersive spectroscopy (EDS) mode were performed with an EDAX model EDXPrime spectrometer. The operation voltages were 15 and $20 \mathrm{kV}$.

For the laboratory X-ray diffraction experiments, both in conventional Bragg-Brentano geometry (XRD) and by grazing incidence (GI-XRD), the gypsum crystal layers were loaded on a flat glass holder and measured in a PANalytical $X$ 'Pert Diffractometer and a PANalytical Empyrean diffractometer, both equipped with a PIXcel3D detector, using $\mathrm{Cu} K \alpha$ radiation, at $40 \mathrm{kV}$ and $30 \mathrm{~mA}$.

Synchrotron 2D GI-XRD measurements were performed at the beamline 11-3 of the SSRL, using a wavelength $\lambda=$ $0.09744 \mathrm{~nm}$. The sample-to-detector distance was $150 \mathrm{~mm}$, and the 2D detector used was an MAR345 with screen pixel dimensions of $0.15 \times 0.15 \mathrm{~mm}^{2}$. Debye rings were integrated using the Fit2D software (Hammersley, 2004).

$\mu$-XRF investigations were carried out at three different synchrotron beamlines: SSRL 2-3 (2-3 $\mu$ m beam spot, SDD detector (Vortex), $13200 \mathrm{eV}$ excitation energy); ESRF ID-21 $\left(0.5 \times 0.5 \mu \mathrm{m}^{2}\right.$ beam spot, SDD X-flash 5100 detector (Bruker), $\quad 7500 \mathrm{eV}$ excitation energy); and Elettra Sincrotrone Trieste, X-Ray Fluorescence $\left(200 \times 100 \mu \mathrm{m}^{2}\right.$ beam spot, SDD X-Flash 5030 detector (Bruker), $13200 \mathrm{eV}$ excitation energy). Selected regions were further examined by $\mu$-XANES analysis. $\mu$-XANES data reduction was performed, either using the software SIXPack (version 1.1) (Webb, 2007) or PyMCA (Solé et al., 2007) and then by averaging replicate scans using the software "Athena" (Demeter 0.9.22) (Ravel and Newville, 2005) after energy calibration.

\section{RESULTS}

\section{A. Chemical-structural characterization of the impurities}

The sections below describe general results, obtained by applying the above-mentioned analytical techniques, and illustrated by the study of representative samples.

\section{Laser confocal microscopy-differential interference contrast}

A LCM-DIM image of the sample CRYD001 surface is presented in Figure 3. The green zone represents the carbon- 


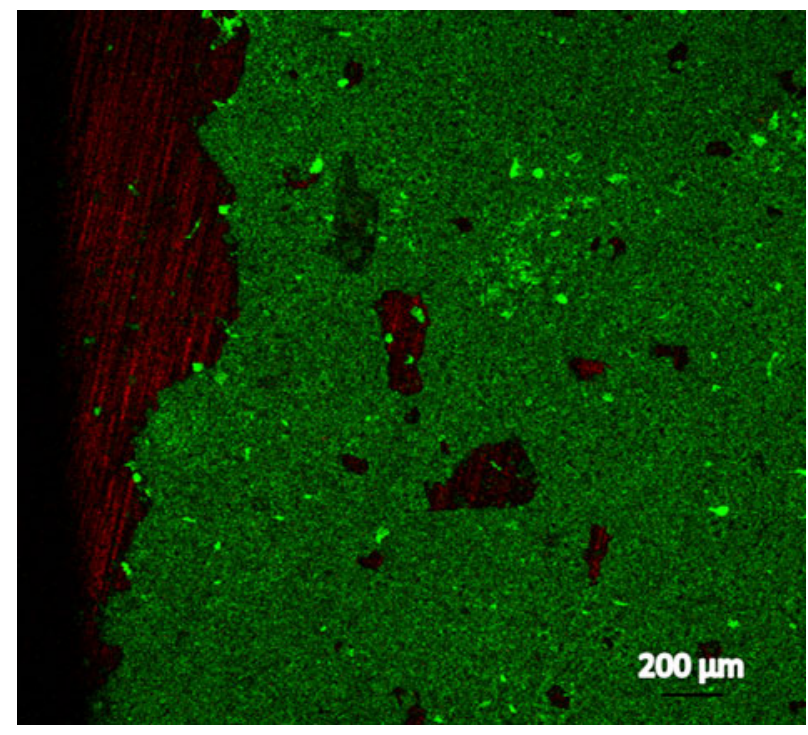

Figure 3. (Color online) LCM-DIM image of the surface sample CRYD001, excited by green $(555 \mathrm{~nm})$ and red $(639 \mathrm{~nm})$ lasers.

rich components, while the black and red zone represents the transparent gypsum substrate.

\section{X-ray diffraction}

GI-XRD analysis was performed on the stain of the CRYD001 sample. The pattern presented in Figure 4 allowed to confirm the carbonated compound, already observed by LCM-DIM, as calcite and dolomite. Also, $\mathrm{SrSO}_{4}$ (celestine) and $\alpha-\mathrm{FeO}(\mathrm{OH})$ goethite were identified.

2D GI-XRD provided the identification of the impurity phases evidenced in Figure 5 for "GYP001" issued from the CC. The following phases were determined: hematite $\left(\mathrm{Fe}_{2} \mathrm{O}_{3}\right)$, cuprite $\left(\mathrm{Cu}_{2} \mathrm{O}\right)$, sphalerite $(\mathrm{ZnS})$, and galena $(\mathrm{PbS})$. Besides, the crystals from the CS (Castillo-Sandoval et al., 2018) also exhibited chalcopyrite $\left(\mathrm{CuFeS}_{2}\right)$ and alabandite $(\mathrm{MnS})$. All these phases are known to be phases that crystallize at temperatures higher than $300{ }^{\circ} \mathrm{C}$, and mostly above $400{ }^{\circ} \mathrm{C}$ (Takeno, 2005).

\section{X-ray fluorescence and X-ray absorption near-edge structure}

The elements most frequently identified as impurities by $\mu$-XRF on the surface of the gypsum samples, from both the $\mathrm{CS}$ and the $\mathrm{CC}$, were $\mathrm{Ti}, \mathrm{Mn}, \mathrm{Fe}, \mathrm{Cu}, \mathrm{Zn}, \mathrm{As}$, and $\mathrm{Pb}$. When cross-correlating the elemental occurrences on the studied surface, the results demonstrated the simultaneous presence of $\mathrm{Mn}$ and $\mathrm{Pb}$, on the one hand, and $\mathrm{Fe}, \mathrm{Zn}$, and $\mathrm{As}$, on the other. Once the presence of the chemical elements has been ascertained, spatially resolved $\mu$-XANES was applied to the elements of interest. $\mu$-XANES allowed identifying the speciation of the element under investigation and by that the specific mineral form(s) which compose the impurities via the position, intensity, and shape of the resulting peak(s) in the spectrum. The results demonstrated that the detected mineral species of $\mathrm{Mn}$ and $\mathrm{Pb}$ were found only as vitreous or amorphous structures. Conversely, the mineral species of $\mathrm{Fe}, \mathrm{Zn}$, and As were identified as crystalline structures.

Figure 6 presents a representative case of the study of a CS crystal (Castillo-Sandoval et al., 2018). Each "pixel" represents a spatial position on the sample. The elemental distributions of $\mathrm{As}-\mathrm{Pb}$ (red), $\mathrm{Zn}$ (blue), and $\mathrm{Fe}$ (green) were retrieved using PyMCA (Solé et al., 2007). After XRF spectral analysis (fitting), we could obtain the relative elemental maps of As (K-edge) and $\mathrm{Pb}\left(\mathrm{L}_{3}\right.$-edge), whose signals are overlapping strongly in the XRF spectra. We could, therefore, select some positions in which one element was in presence, but not the other, or both conjunctly, in order to perform $\mu$-XANES analysis, favoring the positions with the highest elemental concentrations. The combination of relative intensities of these colors allows recognizing the spatial coincidence of the different elements. For example, a dark green pixel suggests the simultaneous presence of $\mathrm{Fe}$ and $\mathrm{Zn}$, and a white pixel, the presence of all three elements. Black pixels correspond to low intensities of the three signals.

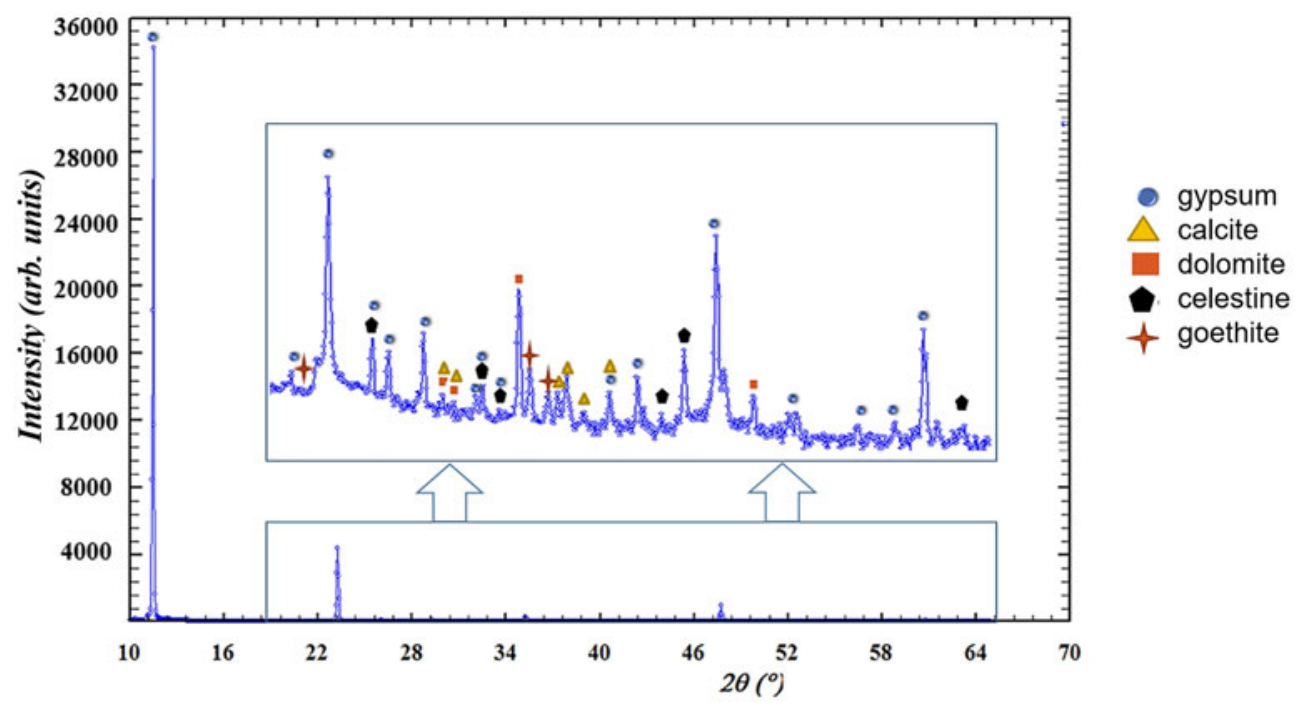

Figure 4. (Color online) GI-XRD pattern of the CRYD001 sample surface, for an incidence angle of $0.5^{\circ}$. The inserted "zoom" pattern is three times amplified from the original pattern. This confirms the presence of the major phases identified with complementary techniques such as LCM-DIM. 


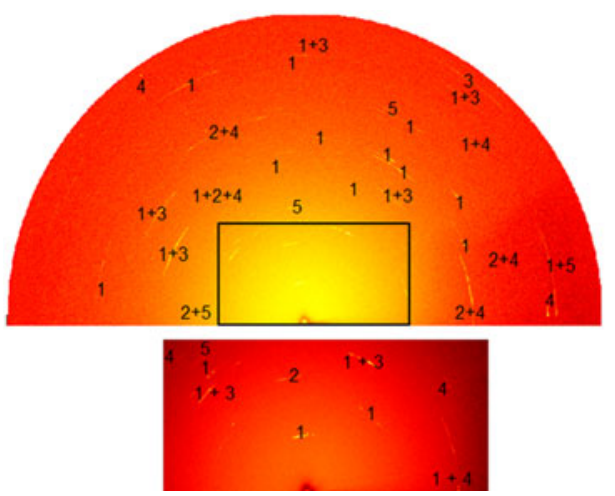

\begin{tabular}{cc}
\hline Phases (\#) & Miller Indexes \\
\hline Gypsum (1) & $020,040,-211,060$, \\
& $-202,071,-233,262,-332$, \\
& $-341,310,202,-363$, \\
& $-341,310,-163,202$, \\
& $-363,341,210,-451$, \\
Galena (2) & $111,022,024,116,004$ \\
Sphalerite (3) & $002,022,113,133$ \\
Hematite (4) & $110,113,222,124,0110,1$ \\
& 34 \\
Cuprite (5) & $111,002,123,113$ \\
\hline
\end{tabular}

Figure 5. (Color online) 2D XRD pattern and interpretation from the sample "GYP001," for an incidence angle of $0.5^{\circ}$. The identification numbers on the spots and/or lines correspond to the phases as described in the table. Figure modified with Copyright permission from Castillo-Sandoval et al. (2015).

While $\mathrm{Pb}$ and As peaks are subject to spectral overlap in the XRF spectrum (emission lines: $\mathrm{Pb} \mathrm{L} \alpha 1: 10551 \mathrm{eV}$ and $\mathrm{As}$ $\mathrm{K} \alpha: 10543 \mathrm{eV}$ ), and thus, the elemental cartographies can be retrieved only after a careful spectral deconvolution and peak fitting, there is no such issue for the acquisition of their XANES spectrum, even if acquired in a fluorescence mode, as the excitation energy for these two elements is significantly different: the As K-edge is characterized by an absorption edge at $11.867 \mathrm{keV}$, while the $\mathrm{Pb} \mathrm{L}_{3}$-edge at $13.035 \mathrm{keV}$. In Figure 6 (left), one can observe the $\mu$-XANES spectra of As showing an intense peak (Castillo-Sandoval et al., 2018).

This study allowed reporting arsenic among the surface impurities of Naica crystals for the first time (CastilloSandoval et al., 2018). Arsenic is an abundant pollutant of Northern Mexico groundwater. It can be presumed that, at least during the final stage of crystal growth, or after, As was present in the groundwater and its presence is, therefore, from natural origin.

Another representative example of $\mathrm{Pb}$ elemental distribution and $\mathrm{Pb} \mathrm{L}_{3}$-edge $\mu$-XANES from the $\mathrm{CC}$ is displayed in
Figure 7. Lead impurities were found at the surface of the crystals in the Naica mines, which was expected as $\mathrm{Pb}, \mathrm{Zn}$, and $\mathrm{Ag}$ ores extraction is the purpose of Naica's mining activities. At the left is displayed the $\mathrm{Fe}, \mathrm{As}-\mathrm{Pb}$, and $\mathrm{Cu}$ correlation map, and the $\mathrm{Pb}$ signal intensity of the same region. At the right is shown $\mathrm{Pb} \mathrm{L}_{3}$-edge XANES spectra collected in fluorescence yield mode on different samples and areas containing $\mathrm{Pb}$ (Castillo-Sandoval et al., 2015).

The combined results of the structural investigations, especially of 2D GI-XRD and $\mu$-XANES, allowed to identify so far during our research, 28 crystallines and two amorphous phases present at the surface of the crystals. As previously mentioned, $\mathrm{Mn}$ and $\mathrm{Pb}$ are contained in amorphous structures. Conversely, the mineral species of $\mathrm{Fe}, \mathrm{Zn}$, and As, detected concomitanly by $\mu$-XRF, are present in crystalline structures that are consistent with the mineral phases present in the mine. In particular, hematite and iron oxyhydroxides prevail among the impurities crystalline phases. Calcium carbonate, as a product of gypsum incongruent dissolution, was not detected in the samples.

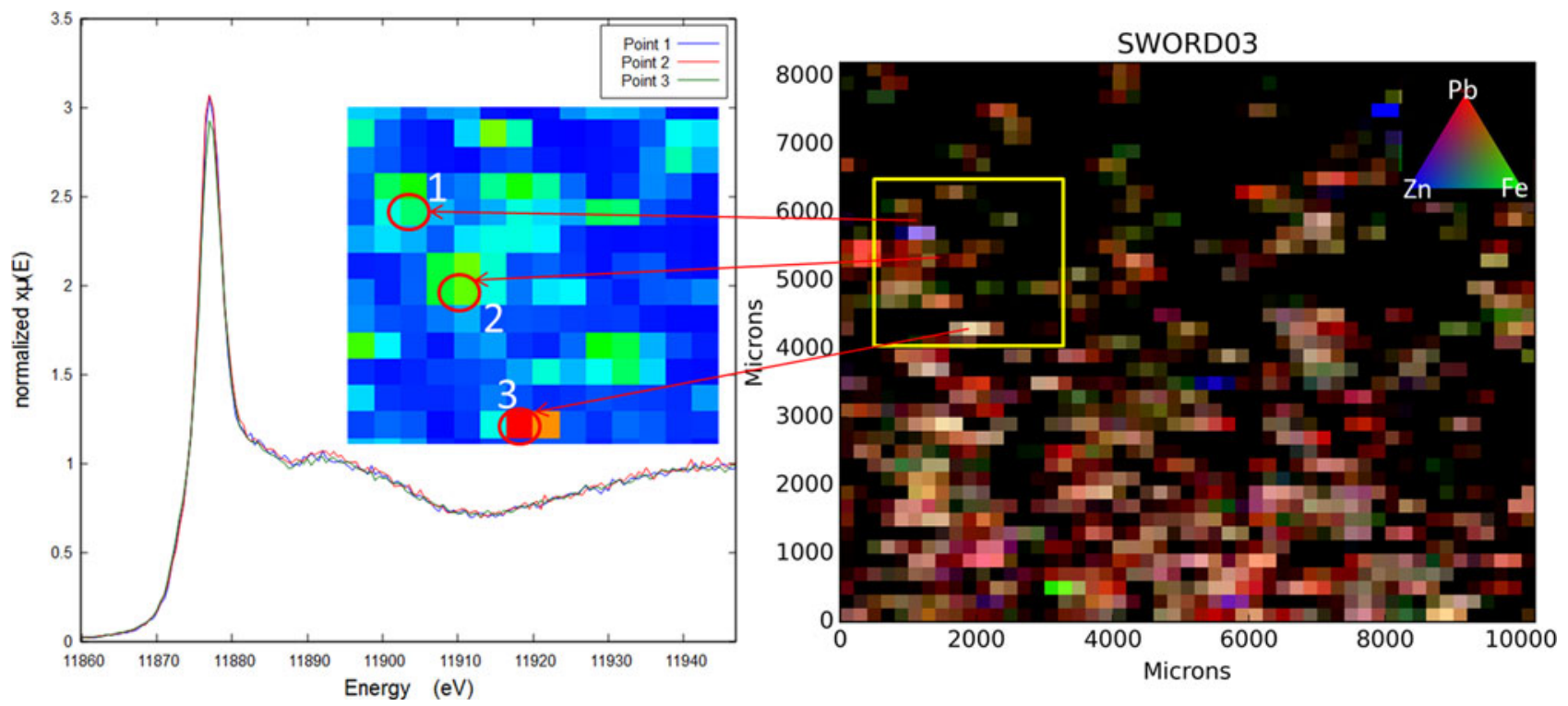

Figure 6. (Color online) Noteworthy results of the sample SWORD03. Left: $\mu$-XANES spectra of the element As three distinct positions of the As elemental map (inset). Arsenic signal intensities are given in a rainbow scale, where red is the most intense. Right: $\mu$-XRF correlation map of Fe, As- $\mathrm{Pb}$, and $\mathrm{Zn}$ concentrations at the sample's surface. The frame in yellow corresponds to the zone where the $\mu$-XANES analysis of As was performed and shown in the inset (left). The arrows indicate the correspondence between pixels in the tricolor map and the map of As concentrations. Data acquired at Elettra - Sincrotrone Trieste, XRF beamline. Figure reproduced with Copyright permission from Castillo-Sandoval et al. (2018). 

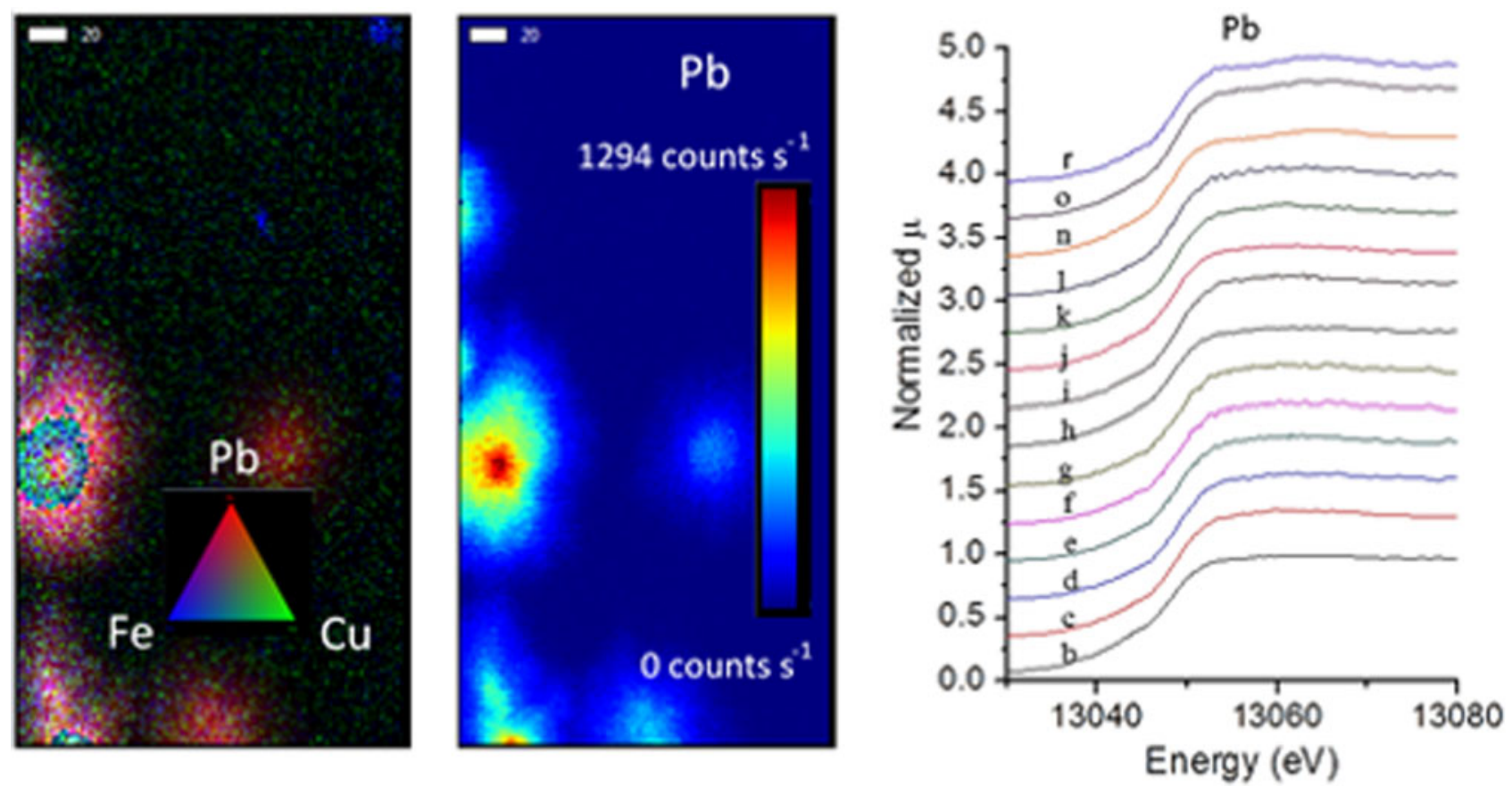

Figure 7. (Color online) $\mu$-XRF mapping of a surface region of sample GYP001 of the CC and $\mu$-XANES spectra of Pb $\mathrm{L}_{3}$-edge from 14 different ROI taken on the four samples GYP001 to 004. Data acquired at the BL2-3 at SSRL. Scale bar: $20 \mu \mathrm{m}$. Figure modified with Copyright permission from Castillo-Sandoval et al. (2015).

The research carried out allowed concluding that the impurities that produce opacity are hematite and goethite, as well as $\mathrm{Mn}$ and $\mathrm{Pb}$ oxides. In conjunction with other data obtained by complementary methods, such as the saturation index, the formulation of the paragenesis of the different minerals, and from the shape and deposition order of the mineral species, it was further confirmed that the impurities have a natural origin. The human action in the Naica caves has been mainly pumping water and extracting some crystal specimens from their natural environment but is not the origin of impurities deposition at the surface of the giant crystals.

\section{B. Experimental simulation of the potential deterioration patterns of the crystals}

To shed some further light on the origin of the impurities, a part of our investigations consisted in reproducing in climatic chambers some plausible environmental conditions in order to perform "accelerating weathering tests" on the crystals (Carreño-Márquez et al., 2015, 2018). One series of tests was performed in a customized climate fog chamber under intermittent conditions (climatic chambers opened and closed regularly, and not fully sealed), and a different one was completed under steady-state conditions (sealed chambers). The following scenarios were expected: surface dehydration with the appearance of bassanite or anhydrite and the deposition of impurities, such as calcium carbonate, especially in experiments under atmospheres of air and $\mathrm{CO}_{2}$.

\section{Intermittent conditions in a microclimatic fog chamber}

This simulation was performed in a Singleton custom-made fog climatic chamber, supplied with water saturated with $\mathrm{CO}_{2}$ and under intermittent conditions (Carreño-Márquez et al., 2015).
Figure 8 presents a diagram of the process occurring in the chamber. $\mathrm{CO}_{2}$ was dissolved by bubbling it into distilled water at room temperature. The solubility of $\mathrm{CO}_{2}$ in water is 0.0326 $\mathrm{kg}^{-1}$ at $25^{\circ} \mathrm{C}$. After $45 \mathrm{~min}$ of bubbling, the $\mathrm{pH}$ of such water produced by carbonic acid was 3.9, which is also the $\mathrm{pH}$ of the created fog. Twenty-four CC gypsum samples, approximately $2 \times 2 \mathrm{~cm}^{2}$ in size, were placed inside the chamber. The experiment went on for about 6 months. The idea was to simulate the irregular door openings of the caves and their effects on the gypsum crystals. Therefore, every 15 days, the chamber was opened, and a couple of samples were removed from the chamber, dried at room temperature, and then weighted in an analytical balance. The chamber was closed, and the rest of the samples were subjected again to air and saturated fog. Since the chamber is not airtight, it is assumed that the fog saturated in $\mathrm{CO}_{2}$ becomes unsaturated fog after a certain time, probably after a few hours, and remains unsaturated fog for the rest of the 15 days (and therefore of more neutral $\mathrm{pH}$ ). The produced effects were probed via optical microscopy and conventional laboratory GI-XRD.

The most evident result of the simulation in the climatic chamber under intermittent conditions was the visible

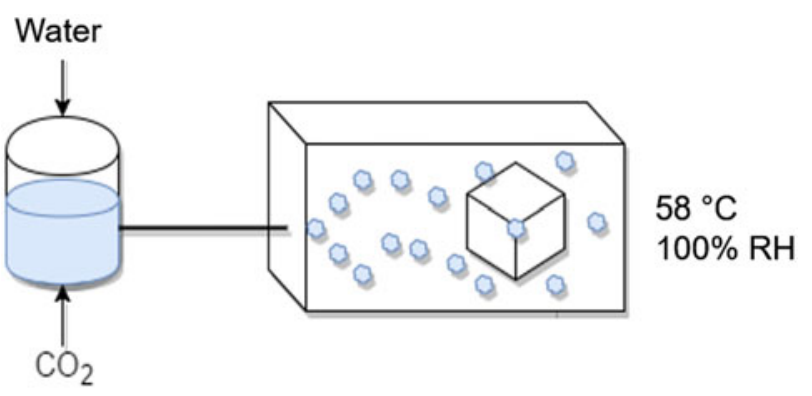

Figure 8. (Color online) Fog generation in the chamber. 

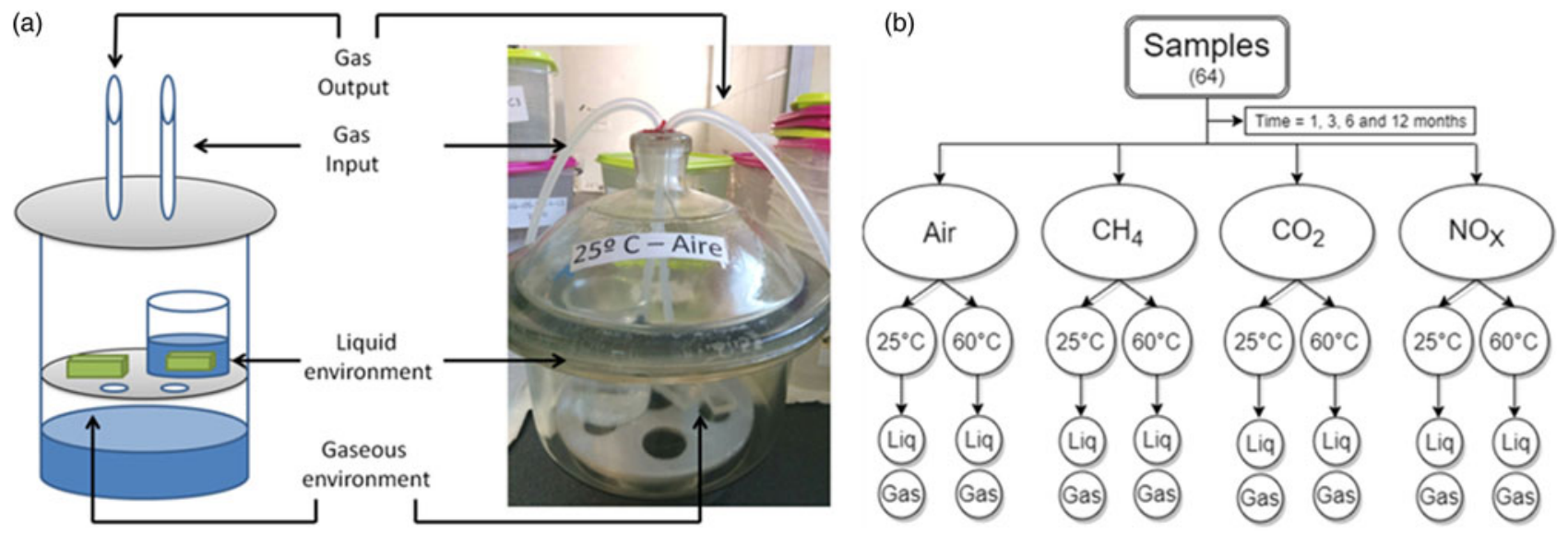

Figure 9. (Color online) (a) Reactor configuration for the conditions of $25^{\circ} \mathrm{C}$ in air and (b) general planning of the steady-state simulation. Figure reproduced from Carreño-Marquez et al. (2018) published under Creative Commons Copyrights.

dissolution of the crystals. Inside the climatic chamber, the condensed fog became water, which was evacuated via the drain. The chemical analysis of the water revealed the presence of 2-3 mg $1^{-1}$ of sulfates, which confirms the dissolution of the gypsum crystals. Furthermore, this dissolution rate is increasing proportionally to the exposition time inside the chamber, between $1 \%$ and $4 \%$ by weight. On the crystal surface, however, calcium carbonate was not detected.

\section{Steady-state microclimatic simulation}

Another series of experiments were performed under steady-state conditions (Carreño-Marquez et al., 2018). Hermetically sealed reactors were prepared and run under controlled conditions of liquid and gas proportion, gas saturation vapor, temperature and relative humidity.

Four different environmental conditions rich in $\mathrm{CO}_{2}$, $\mathrm{CH}_{4}, \mathrm{NO}_{x}$, and air were tested at two different temperatures of 25 and $60{ }^{\circ} \mathrm{C}$, and in either liquid (L) or gaseous (G) environments. Samples were removed from the chamber without replacing them at the increasing time intervals of $1,3,6$, and 12 months. For doing this, the chambers were opened for brief moments, and the conditions were restored to continue the experiments. One sample for each experimental condition (no replicate) was studied. In total, 64 different experimental conditions were probed. The scheme of these experiments is presented in Figure 9.

The formation of bassanite $\left(\mathrm{CaSO}_{4} \bullet \frac{1}{2} \mathrm{H}_{2} \mathrm{O}\right)$ or anhydrite $\left(\mathrm{CaSO}_{4}\right)$ calcium sulfate, as a result of gypsum dehydration, and the formation of calcium carbonate following a reaction with atmospheric $\mathrm{CO}_{2}$ were all monitored by mid-infrared spectroscopy (PerkinElmer Spectrum 400, spectral range $4000-450 \mathrm{~cm}^{-1}$ ). Because only bassanite was found with concentration above the detection limits, its formation was studied in more detail. The surface of the crystals was directly exposed to infrared radiation with no further treatment. Laboratory and synchrotron radiation GI-XRD, for 48 of the 64 experimental conditions, and optical microscopy were also applied to ensure the characterization of the crystals as complete as possible.

In the work of Carreño-Marquez et al. (2018), a semiquantitative dimensionless descriptor of the relative amount of bassanite ( $\mathrm{RAB}$ ) has been defined for each experimental condition. To calculate $\mathrm{RAB}$ values, the following parameters were taken into account: (1) the detection of the $1180 \mathrm{~cm}^{-1}$ band attributed to bassanite in the infrared spectra; (2) the number of bassanite peaks in the GI-XRD (lab and synchrotron) patterns; and (3) the relative intensity of the bassanite XRD peaks. Each indicator was normalized to one, dividing by the highest value observed in the whole experimental simulation. The sum (maximum value 3 ) was interpreted as a deterioration index due to the gypsum dehydration in each sample - conditions of the experiment.

The results of RAB values were analyzed according to their assessed statistical significance. They are presented in Figure 10. The graphic presents the tendencies of the RAB averages for the six feasible combinations of the independent parameters: four atmospheres (air, $\mathrm{CO}_{2}, \mathrm{CH}_{4}$, and $\mathrm{NO}_{x}$ ); two temperatures $\left(25\right.$ and $\left.60^{\circ} \mathrm{C}\right)$; three exposure times $(3,6$, and 12 months); and two environments ( $\mathrm{L}$ and $\mathrm{G})$. The table in Figure 10 contains the mean values $\epsilon$ and the standard deviations $\sigma$ of the total 48 experimental RAB indexes, and of the 24 values for the two selected temperatures, 24 values for each different environment, 16 values for each different exposure time, and 12 values for each different atmosphere.

After these series of microclimatic simulations under a steady-state environment, the following conclusions can be drawn. For 1 and 3 months' periods of exposure, and regardless of the type of atmosphere or temperature, the modification of the appearance of the crystals, in the form of opacity, small pits, the formation of different kinds of roughness, or small fractures of the surface, was the most relevant aspect, without any chemical/structural alteration. Additionally, it was observed that for longer periods of exposure to these microclimatic conditions, the surface defects tend to disappear, and the surface reaches some chemical equilibrium that dissolves and recrystallizes calcium sulfate. Last, the formation of bassanite resulted from the dehydration of the gypsum phase, which occurred more likely in a gaseous environment. The experiments in air and under $\mathrm{CO}_{2}$ atmospheres were the ones that produced the highest proportions of bassanite on the crystal surfaces. No calcium carbonate was detected in the experiments under steady-state conditions. More details are provided in Carreño-Marquez et al. (2018). 


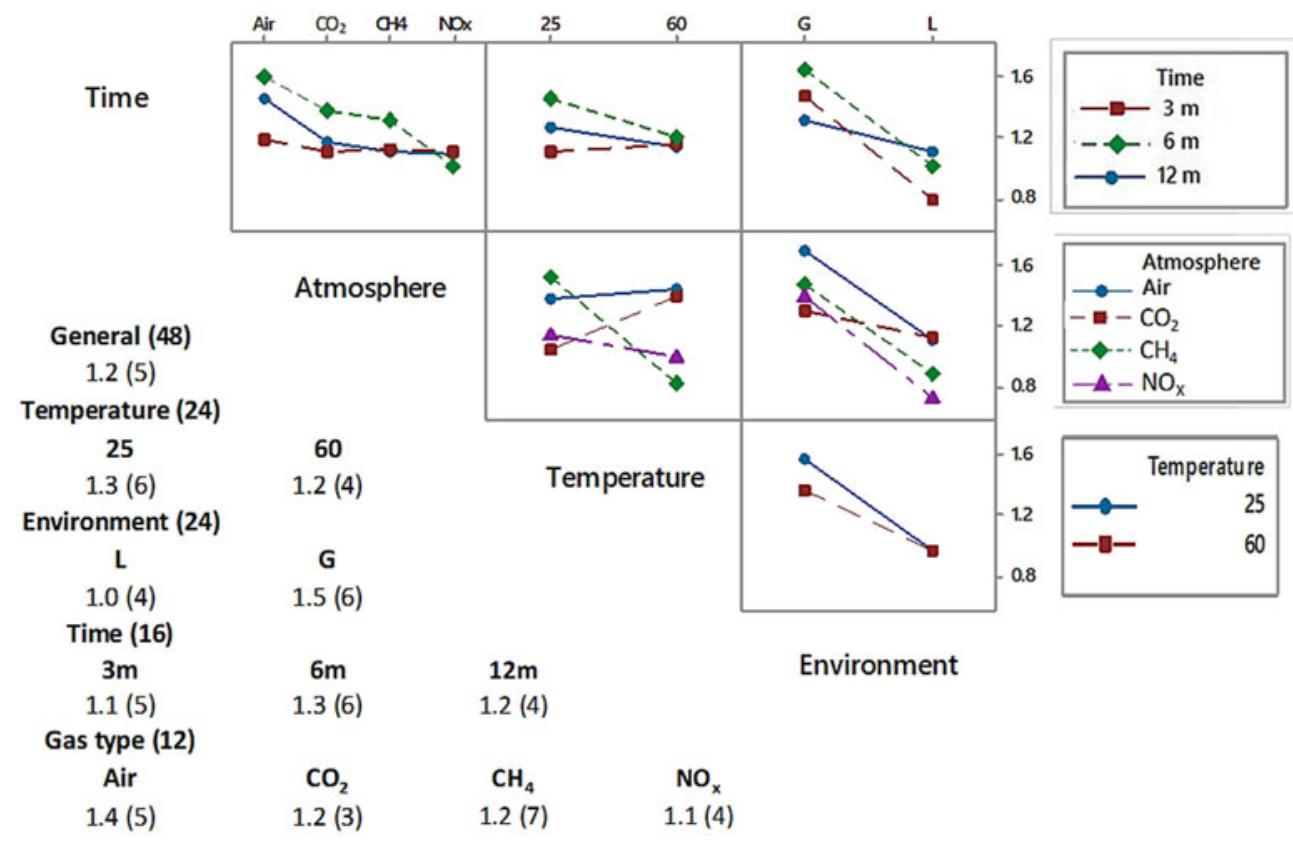

Figure 10. (Color online) Top right: Statistical RAB graphical tendencies of the simulation in steady but "accelerated" weathering conditions. In the graph, the average RAB values appear in the ordinates on the right. The legend of the values of the fixed parameters of Time, Atmosphere, and Temperature are presented in boxes on the extreme right. The independent parameters Atmosphere, Temperature, and Environment are presented in the abscissa, in the upper part of the figure. Bottom left: Table of the mean values $\epsilon$ and the standard deviations, taken over the total 48 experimental RAB indexes, and over the 24 values for each temperature, the 24 values for each environment, the 16 values for each exposure time, and the 12 values for each atmosphere. These values are presented in " $\epsilon(\sigma)$ " format. The time and temperatures are given in months $(\mathrm{m})$ and ${ }^{\circ} \mathrm{C}$, respectively. L and G represent liquid and gaseous environments. Figure modified from Carreño-Marquez et al. (2018), published under Creative Commons Copyrights.

\section{CONCLUSION}

The chemical and structural characterizations performed on the impurities at the surface of the Naica giant crystals, presented in Section III.A, reveal that hematite $\left(\mathrm{Fe}_{2} \mathrm{O}_{3}\right)$, sphalerite $(\mathrm{ZnS}), \gamma-\mathrm{MnO}_{2}$, and galena $(\mathrm{PbS})$ are the species present in the highest proportions. Hematite was even found systematically as a surface impurity in all studied samples. Other phases, which were non-detectable by XRD techniques, were identified by micro-characterization such as $\mu$-XRF and $\mu$-XANES. They are probably products of the natural adsorption on hematite or other iron oxy-hydroxides. Geochemical considerations suggest, however, that the impurities are not anthropogenic, but mostly the product of the natural evolution of the crystals in the changing environment of the caves.

The microclimatic simulations presented in Section III.B shed light on the degradation processes to which the crystals are currently exposed. In particular, surface alteration and dissolution of the crystals in the liquid environment were observed for short exposition times, as well as the formation of bassanite $\left(\mathrm{CaSO}_{4}{ }^{\bullet 1} / 2 \mathrm{H}_{2} \mathrm{O}\right)$. Neither anhydrite nor calcite was detected. Gaseous environments revealed to be the most detrimental conditions to the gypsum crystals' integrity. This constitutes a severe issue if, for mining activities, the natural underground water is extracted from the Naica caves.

Nonetheless, the exploitation conditions of the mine are changing. Eventually, as it is at the date this article is written, the mine is closed, and the groundwater level could rise in the area. However, the area's groundwater is overexploited for human consumption and agriculture, so presumably the dynamic level of the wells would not reach $-300 \mathrm{~m}$. If ever this occurs, the water will flood the $\mathrm{CC}$, thus stopping the dehydratation of the crystals.
There is also the possibility that decision makers keep the CC potentially accessible to man. It would be highly recommended to keep the visits frequency and numbers of entrances to a minimum, in order to maintain the humidity level inside the cave as high as possible. It is also advisable to improve the lock system for the entrance to the CC. In any case, it is necessary to carry out a conservation project for this exceptional gift of Nature.

\section{ACKNOWLEDGEMENTS}

The support provided by CONACYT Project No. 183706, the proposals SSRL 3939, the ESRF HG-77, Elettra Sincrotrone Trieste 20155328, as well as by the International Centre for Theoretical Physics (ICTP) are acknowledged. The support in laboratory and synchrotron radiation measurements of Ernesto Guerrero and Guillermo Herrera of CIMAV, Ulises Salazar of the Autonomous University of Puebla and José M. Nápoles of the UACh is appreciated. Special thanks to Dr. Manuel Reyes-Cortés, who provided some of the key research samples and supported their selection and analysis. The authors thank the cooperation of Angels Canals, the management of the Peñoles company, the Desert Museum of Ciudad Delicias, Chihuahua, the Harvard Museum of Natural History, and the Faculty of Engineering of the Autonomous University of Chihuahua for providing essential specimens for the study.

Carreño-Márquez, I. J. A., Castillo-Sandoval, I., Esparza-Ponce, H. E., Fuentes-Cobas, L. E., and Montero-Cabrera, M. E. (2015). "Characterization of gypsum crystals exposed to a high $\mathrm{CO}_{2}$ concentration 
fog using X-ray," in XI International Symposium on Radiation Physics, Vol. 1671, edited by G. Espinosa and J. Lopez (AIP Conf. Proc., Ciudad Juarez, Mexico), p. 7.

Carreño-Márquez, I. J. A., Menéndez-Méndez, E., Esparza-Ponce, H. E., Fuentes-Cobas, L., García-Rovés, R., Castillo-Sandoval, I., Luna-Porres, M., De-Frutos-Vaquerizo, J., and Montero-Cabrera, M. E. (2018). "Naica's giant crystals: deterioration scenarios," Cryst. Growth Des. 18, 4611-4620.

Castillo-Sandoval, I., Fuentes-Cobas, L. E., Fuentes-Montero, M. E., Esparza-Ponce, H. E., Carreno-Márquez, J., Reyes-Cortes, M., and Montero-Cabrera, M. E. (2015). "Light in the darkening on Naica gypsum crystals," in XI International Symposium on Radiation Physics, Vol. 1671, edited by G. Espinosa and J. Lopez (AIP Conf. Proc., Ciudad Juarez, Mexico), p. 9.

Castillo-Sandoval, I., Fuentes-Cobas, L. E., Pérez-Cazares, B. E., Esparza-Ponce, H. E., Fuentes-Montero, M. E., Castillo-Michel, H., Eichert, D., Reyes-Cortes, I., Carreño-Márquez, I. J., Napoles-Duarte, J. M., and Montero-Cabrera, M. E. (2018). "Surface impurities on giant gypsum crystals from "la Cueva de las Espadas" (Cave of Swords), Naica, Mexico," Mineral. Petrol. 112, 865-879.

Hammersley, A. P. (2004). FIT2D V12. 012 Reference Manual V6. 0. ESRF International Report No. ESRF98HA01 T. Program. Available at: http:// www.esrf.eu/computing/scientific/FIT2D.
Ravel, B. and Newville, M. (2005). "ATHENA, ARTEMIS, HEPHAESTUS: data analysis for X-ray absorption spectroscopy using IFEFFIT," J. Synchrotron Radiat. 12, 537-541.

Solé, V., Papillon, E., Cotte, M., Walter, P., and Susini, J. (2007). "A multiplatform code for the analysis of energy-dispersive X-ray fluorescence spectra," Spectrochim. Acta B 62, 63-68.

Takeno, N. (2005). Atlas of Eh-pH Diagrams. Intercomparison of Thermodynamic Databases (National Institute of Advanced Industrial Science and Technology, Geological Survey of Japan, Tokyo, Japan).

Van Driessche, A. E. S., García-Ruíz, J. M., Tsukamoto, K., Patiño-Lopez, L. D., and Satoh, H. (2011). "Ultraslow growth rates of giant gypsum crystals," Proc. Natl. Acad. Sci. 108, 15721-15726.

Van Driessche A. E. S., Stawski, T. M., Benning L. G, and Kellermeier, M. (2017). "Calcium sulfate precipitation throughout its phase diagram," in New Perspectives on Mineral Nucleation and Growth: From Solution Precursors to Solid Materials, edited by A. E. S. Van Driessche, M. Kellermeier, L. G. Benning and D Gebauer (Springer International Publishing, Cham), pp. 227-256.

Van Driessche, A. E. S., Stawski, T. M., and Kellermeier, M. (2019). "Calcium sulfate precipitation pathways in natural and engineering environments," Chem. Geol. 530, 119274.

Webb, S. (2007). Sam's Interface for XAS Package SixPACK (SSRL, Menlo Park, CA). 